\title{
Mental Disorders and Work Integration: A Retrospective Study in a Northern Italian Town
}

\author{
Chiara Buizza ${ }^{1, *}$, Rosaria Pioli ${ }^{2}$, Sara Lecchi ${ }^{2}$, Chiara Bonetto ${ }^{3}$, Anna Bartoli $^{4}$, Renzo Taglietti ${ }^{4}$, \\ Alberto Ghilardi ${ }^{1}$ and Eugenio Riva ${ }^{5}$
}

${ }^{1}$ Unit of Dynamic and Clinic Psychology, Department of Clinical and Experimental Sciences, University of Brescia, Italy; ${ }^{2}$ IRCCS "St. John of God" Fatebenefratelli, Brescia, Italy, ${ }^{3}$ Department of Medicine and Public Health, University of Verona, Italy; ${ }^{4}$ Local Health Authority of Brescia, Italy; ${ }^{5}$ U.R.A.Sa.M Lombardy, Milan, Italy

\begin{abstract}
Objectives: The present study was conducted in a vocational integration service of a northern Italian town with two major aims: to assess vocational integration programs undertaken from $1^{\text {st }}$ January 2004 to $1^{\text {st }}$ January 2007; and to identify job tenure-associated predictors.

Methods: This is a retrospective study; we collected data such as gender, age, duration, type and outcome of the vocational integration program, and number of interventions performed by the vocational integration service. Self-report questionnaires were also used to assess the satisfaction of users, caregivers, practitioners, and of the company contacts involved in the study.

Results: The service has enrolled 84 users during the observation period. Out of these users, $64.3 \%$ of them still had their jobs after three years. Users, caregivers and company contacts expressed high levels of satisfaction for the support received by the vocational integration service. The company expressed less satisfaction for the collaboration received by the Departments of Mental Health (DMHs) that coached the users. The only variable associated to the outcome was the number of interventions that the users received before their placement on the job.

Conclusions: Despite all the limits of this study, its results show that the chance of taking advantage of a supported job placement service has likely proven itself effective in helping people with mental disorders to obtain and maintain a competitive employment. Our results, however, also point to the necessity of implementing newer strategies meant to develop a greater integration among all services dealing with mentally ill people.
\end{abstract}

Keywords: Mental disorders, outpatients, retrospective study, job tenure, satisfaction, vocational integration.

\section{INTRODUCTION}

A chance to work represents an important goal for many people with mental disorders and it is one of the main elements protecting them from the possibility of developing, or worsening, problems of mental health, as well as it being a real possibility of experimenting an adequate level of community integration [1].

Innovative experiences demonstrated that offering employment reduces patients risk of new hospitalizations and of their becoming chronic, establishing positive dynamics that improve their social fitness and clinical recovery [2]. Nevertheless, the lack of employment represents one of the more relevant problems for people with mental disorders [3, 4]. It is estimated that about $85 \%$ of people with serious mental disorders are unemployed [5-7], and that the rate of their access to the labor market is approximately half the rate of people with other types of disability: physical, intellective, sensorial $[8,9]$.

*Address correspondence to this author at the Unit of Dynamic and Clinic Psychology, Department of Clinical and Experimental Sciences, University of Brescia, Viale Europa 11, 25123 Brescia, Italy; Tel: +39 030 3717429; Fax: +39 030 3717207; E-mail: buizza@med.unibs.it
Studies on this topic are cluster able into three main areas of interest: 1) studies that analyze which variables predict a return to work, following prolonged absence; 2) studies that assess the elements associated with absenteeism; 3) studies examining variables predicting job maintenance by people with mental illness.

Studies on return to work show that only $50 \%$ of people who are absent from work for more than six months return to their previous employment afterward [10]. The most predictive factors are the presence of good cognitive functions, good medical conditions, the presence of social support and skills, previous work experiences, and the presence of an established good therapeutic relationship, both with the key reference practitioner, and with the practitioner for work integration $[11,12]$.

Studies that have assessed absenteeism revealed that being a male, having an early onset of mental disorder [13], receiving little support from colleagues, and being in a general condition of reduced social support [14] are elements associated to greater absence from work. In addition, a heavy workload, risky behaviors, and the existence of some specific disorders, such as major depression, dysthymia, phobia, and use of street drugs are associated to repeated and pro- 
longed absences from work [15]. Moreover, these studies have highlighted that returning to work after six months was predictive of a subsequent decline of depressive symptoms.

Studies that have assessed job maintenance by people with mental illness have shown that about $70 \%$ of those participating to a program such as Individual Placement and Support (IPS) keep their work longer over time [16, 17]. The IPS model was developed to provide supported employment services to people with severe mental disorders. IPS used a team approach to integrate mental health and vocational services. Mental health centers hired employment specialists who, in order to ensure coordinated services, directly joined the participating clinical teams. Rather than providing preemployment assessment and training for job-related activities, IPS employment specialists began helping their patients to find a job immediately and, after having secured their employment, they trained them and followed-along as needed. IPS employment specialists assumed that their patients would have learnt job skills and made-up their minds about their work preferences, whilst on the job, rather than through pre-employment counselling and training [18].

A longitudinal study, based on an IPS that studied a cohort of people for ten years, demonstrated that most people were still working at follow-up and that about one third of them had been on the job for at least five years, whenever working part-time jobs, and that they were competitively paid [19]. A further study, which assessed the state of occupation after 8-12 years, showed that all the subjects involved were still working at follow-up time: $82 \%$ were in a competitive job, whilst $71 \%$ of them had worked for more than half of the follow-up years taken into consideration [20]. The most predictive variables were symptoms remission, having had previous work experiences and experimenting a good level of work satisfaction. Another study, carried out on patients with psychotic disorders, showed that having a specialist assigned to the patient work place predicts maintenance time in a competitive job at the 24 months follow-up [21].

All studies reported above show that the presence of previous work experience and higher cognitive levels of memory, attention, and executive functions are associated with a greater number of working hours and higher payoff. On the contrary, cognitive impairment is associated with the need of greater support at the workplace and with the request for more contacts with the mental health care providers.

Other studies, carried out on patients with psychosis, show that coping skills and social support are more important for the management of their illness than for facing any other problem at their workplace. Conversely, the latter mostly benefit by supporting company staff and by colleagues sympathetic to mental health problems of their peers [22].

In another study, which investigated the working reality of people with schizophrenia in UK, France and Germany it emerged that the probability of having and keeping a job is associated with factors such as: younger age, higher education, reduced symptoms prevalence, and family life. Conversely, the probability of being employed is hampered by disorder chronicity, early onset, substance abuse [7], and receiving supplementary incomes, linked, or not, to any disability $[23,24]$.
Beyond the above-mentioned ones, there are further causes, not always due to mental health problems, or any other characteristics of the work environment, which limit occupational projects and which are. The Italian condition is likely mainly characterized by insufficient integration among care programs, mental health rehabilitation services and the employment ones. On stage, there is also: a poor support, by psychiatric services, toward individual work integration, likely due to the absence of a specific culture in this area; the lack of specific resources for work-related projects; the lack of systematic assessment procedures of the existing vocational integration programs, which precludes the possibility of meaningful comparison in scientific studies; the poor competence of the psychiatric services in the work rehabilitation fields and the workforce shortage of the functional and multidisciplinary teams specialized in this field.

All the above address the problem of disciplinary integration and the consideration that rehabilitative approaches and their response patterns at work are neither univocal, nor definitive present themselves today [25]. Their heterogeneity influences the clinical practice, which in Italy is not always clearly defined. Data are lacking on both the outcomes of the vocational placement services and on the professional and organizational models at work in this field of Italian society.

This is a retrospective study, conducted at vocational integration service of a town in northern Italy; it had two major aims: a) to assess programs for vocational integration active from $1^{\text {st }}$ January 2004 to $1^{\text {st }}$ January 2007 ; b) to identify job tenure-associated predictors. We hope that the results of this study could help implementing new strategies and promote a reflection on the development of good standard procedures to improve joint ventures on vocational integration between mental health services and the public and private/social employment-dedicated activities.

\section{MATERIALS AND METHODS}

\section{Sample}

The study was carried out on all users with mental disorders of a vocational placement service by the Working Integration Unit (WIU) of the Local Health Authority of Brescia. The costs of the service were covered by the Lombardy Region. The period of reference goes from $1^{\text {st }}$ January 2004 to $1^{\text {st }}$ January 2007.

\section{The Working Integration Unit (WIU)}

This Unit carries out second level activities on users, compared to the overall rehabilitative project carried out by the Department of Mental Health (DMHs). Successful completion of a vocational placement program requires three steps: assessment, job search, and coaching.

\section{Assessment}

The WIU team is composed of psychologists and educators. The 'interview' is the principal tool used in this setting and it is aimed at gathering personal and work history, desires, and motivations of people with mental disabilities addressed there by mental health services. Following the outcomes of these assessments, a vocational placement program is developed, trying to fit user's job 
preferences and to find out a work environment characterized by availability and elasticity.

\section{Job Search}

During this phase, an evaluation of the required tasks and of the user characteristics is performed. As soon as a job compatible with the user characteristics is found, a curriculum vitae of the candidate worker is sent to the potential employer. The potential employer is also informed about the vocational placement program that should be pursued (internship, placement internship, direct employment). If the potential employer agrees with the proposal, the potential new employee accompanied by his/her tutor, is introduced to the former. The potential employer is never explicitly informed about the mental disorders of the to-be-hired patient, whilst these are introduced using more easily understood words, that will be chosen also to be more job-related and stressing the skills and the limits of the potential new worker. During this first meeting with the potential new employer, he/she will also be offered the opportunity to clarify doubts and misgivings about the concept of psychic disability. If the introduction will have satisfied both potential partners, targets, times and instruments necessary to the fulfilment of a successful employment will be jointly assessed.

Usually, an internship is the preferred tool apt to mediate between corporate demands of the employer and patient needs.

\section{There are two different internship varieties:}

- internship (DM 142/98) is aimed at the assessment of working skills, at the promotion of abilities and at training specific tasks; it is directed at users who present a favorable prognosis about their employment;

- placement internship (Art. 11, Law 68/99) is aimed at the improvement of working places, at the acquisition of self-organizational skills and at training specific tasks that will prove their worth whenever the candidate will be employed. This training is meant for those job candidates who have already completed an internship and will likely successfully complete their employment.

Conversely, the 'Direct employment' is geared towards users who are already able to obtain the competitive job directly, following the principles of the IPS model.

\section{Coaching}

During this phase, the educator will accompany his/her patient, while being on the job. The educator duty is mediating between corporate demands and patient needs. Moreover, the educator will, mediate/communicate with anyone who, besides his/her role, can help achieving the goals foreseen by the vocational placement program. This sidestepping takes place with different times and models for any different user. In addition, any different user is supported by a corporate tutor whose role is teaching him/her some job-necessary skills. Periodically, some check-up meetings are hold that are participated by, both, the employer and the vocational placement service.

\section{Italian Labor Laws for People with Disability}

In Italy, there is a law establishing norms concerning job rights of disabled people (Law 68/99). This law is meant to improve vocational employment of disabled people, through supporting services and targeted placement. According to article 2 of Legislative Decree, $n^{\circ} 509$, enacted by the Italian Ministry of Health, on November 23, 1988, borrowing from the International Classification of Impairments, developed by WHO, 'disabled people' are considered persons with physical, mental, sensorial, or intellectual impairment, resulting in a reduction of working capacity greater than $45 \%$.

According to the above mentioned law, Companies employing from 15 to 35 workers, are compelled to hire at least 1 disabled worker, whilst companies whose number of employees range from 36 to 50 , have to hire at least 2 disabled workers. Finally, companies with more than 50 employees have to employ at least $7 \%$ of their work force from disabled people cohorts.

Disadvantaged people are, instead, all those who belong to the following categories: physically and/or sensorial disabled previous patients from psychiatric institutes; subjects undergoing psychiatric treatment; drug-addicts; alcoholics; minors of working age with family difficulties; people with sentences alternative to detention in specific situations provided by Italian law. Moreover, 'Disadvantaged person' is also considered anyone who belong to specific categories labeled accordingly by any Ministry decree. Disadvantaged people are often employed by so-called "social cooperatives" where they work at different chores (agricultural, industrial, commercial or part of the third sector), according to a specific Italian law enacted in 1991. According to this law, disadvantaged people should be at least $30 \%$ of the social cooperatives workforce. Users working in a social cooperative are usually considered having a competitive employment. As in other studies [26], criteria for competitive employment included: pay at minimum wage, or higher, employment in a mainstream integrated setting, the job not having been specifically set-up for mental health patients, and it being held independently (i.e., not controlled by a service agency).

\section{Instruments}

The assessment of the characteristics of the vocational integration program(s) was attained through an ad hoc instrument. This collected data such as gender, age, duration and category of the program received (internship, placement internship, direct employment), outcome of program (interruption, passage to placement internship, employment), number of interventions received by the practitioners of the WIU, monitoring on the work place, company assessment, individual and group assistance.

A self-assessment questionnaire was also used to assess the level of satisfaction of users, caregivers, practitioners of the WIU, and company contacts.

The questionnaires provide answers, assessed by a 5 points Likert scale (where 1 corresponds to completely dissatisfied and 5 to completely satisfied), or open spaces to leave comments.

\section{Statistical Analysis}

Statistical association between categorical variables were assessed through Chi-square tests, or Fisher's exact probabil- 
ity ones, whenever at least one of the expected frequencies was smaller than 5. Differences between the means of continuous variables were assessed using ANOVAs. Instead, correlations between continuous variables were computed using Pearson's correlation coefficients. All test were twotailed and the probability of a type I error was set as $p<0.05$.

Stepwise multivariate logistic regression were used to fit the effect(s) of a set of independent variables on the outcome of interest (positive versus negative). As positive outcome, we refer to a condition of job maintenance at January $1^{\text {st }}$ 2007; and a negative outcome is instead an employment loss before the just mentioned date.

All analyses were performed using either the SPSS 14.0, or the Stata 8.0 statistical package for Windows.

\section{RESULTS}

\section{Characteristics of the Users}

All the 84 users who had access to the service from January $1^{\text {st }} 2004$ to January $1^{\text {st }} 2007$ were considered in the retrospective study. Sixty-nine percent of them were male, and their average age was 37.6 years $(\mathrm{SD}=8.2$; range: $21-58$ ). Eighty-one percent of the individuals in the sample were disabled and $19 \%$ of them were in a disadvantaged condition according to Italian Laws.

According to the ICD-10, $48.1 \%$ of patients suffered from psychosis, $20.8 \%$ from mood disorders, $19.5 \%$ from personality disorders, and $5.2 \%$ from anxiety disorders. Only $6.5 \%$ presented comorbidity. The diagnoses were made by the treating clinicians of the Mental Health Service, who then sent the patients to the WIU.

\section{Type and Duration of the Vocational Integration Pro- grams}

During the period taken into consideration, the 84 users entered 128 work programs overall, whose 77 were direct employments, 37 were placement internships, and 14 were internships. Out of these 84 users, 47 of them entered one program, 30 of them entered two programs, whilst 7 of them participated to three programs (Table $\mathbf{1}$ ).

\section{Users' Outcome}

In January 2007, 54 (64.3\%) users were still employed: 34 of them worked in companies, whilst 20 more worked in social cooperatives. Almost half of the patients (48.2\%) suffered from psychosis, $24.1 \%$ from mood disorders, $20.3 \%$ from personality disorders, $3.7 \%$ from anxiety disorders, and $3.7 \%$ from personality disorders in comorbidity with substance abuse.

Of the 29 users who experienced a negative outcome, 14 were working in companies and 15 in social cooperatives, 1 user died. In 26 cases, the main cause of the unfavorable outcome was the decision of quitting the job by the user: himself/herself. In $69.2 \%$ of cases, the patient interrupted his/her job experience because of a relapse, worsening his/her psychopathological conditions that had become incompatible with committing to a job afterward. Finally, $30.8 \%$ of users interrupted their job experience because of a variety of other reasons, e.g., because they moved to another city, or because they experienced their work as unsuitable, or too difficult. Just in 3 cases, the decision to terminate the work experience, or to overlook the renewal of the contract, was taken by the employer.

Table 1. Type and Duration of the Vocational Integration Program (N=128)

\begin{tabular}{|c|c|c|}
\hline & $\mathbf{N}$ & $\begin{array}{c}\text { Duration in months } \\
\text { Average (sd) } \\
\text { Median; range }\end{array}$ \\
\hline \hline Internship (N=14) & & \\
Social cooperative & 9 & $6.2(3.5)$ \\
$\quad$ Company & 5 & $6.0 ; 1-14$ \\
\hline Placement Internship (N=37) & & \\
Social cooperative & 12 & $3.5(2.0)$ \\
Company & 25 & $3.0 ; 1-11$ \\
\hline Direct Employment (N=77) & & \\
Social cooperative & 33 & $9.1(7.0)$ \\
Company & 44 & $7.0 ; 0-24$ \\
\hline
\end{tabular}

\section{Number of Interventions Received}

No statistically significant differences were found between those users who had had positive outcomes and the ones who had had a negative one on the total number of interventions that they had received by the practitioners of the WIU, before and after the work placement.

Equally, no statistically significant differences were found between the two groups of users (positive versus negative outcome) compared to the overall number of interventions received before the work placement, stratified by type. The only exceptions were the number of phone calls made to the patient $(\mathrm{p}=.009)$ and the number of phone calls made to the company $(\mathrm{p}=.001)$, that, in both cases, are higher in patients who had a negative outcome.

Finally, even for what concerns the comparison between overall number of interventions, received after the work placement in the company or in the social cooperative, there are no statistically significant differences between the two groups. If the interventions, stratified by type, are taken into consideration, a greater number of review meetings in the company was observed in the group of users who had a positive outcome $(p=.033)$.

\section{Satisfaction of the Users}

Sixty-six questionnaires were collected: $69.7 \%$ of those who filled in the questionnaire were males, the average age was 38 years ( $\mathrm{SD}=8$; range: $21-56)$. Almost half of the users $(47.5 \%)$ suffered from psychosis, $21.3 \%$ from mood disorders, $4.9 \%$ from anxiety disorders, $21.3 \%$ from personality disorders and $4.9 \%$ from mood disorders in comorbidity with personality disorders. Of these, 66 users $(45.5 \%)$ worked in social cooperatives. The outcome in January 2007 was unfavorable for half of them.

The area in which the users expressed their greater level of satisfaction was the support received by the providers of the WIU, followed by the collaboration received from colleagues in the workplace (Table 2). 
Table 2. Satisfaction of the Users $(N=66)$

\begin{tabular}{|c|c|}
\hline $\begin{array}{c}\text { Overall Satisfaction } \\
\text { Average }(s d)\end{array}$ & $4.03(0.89)$ \\
\hline \multicolumn{2}{|l|}{ Actual work } \\
\hline Totally unsatisfied & $6.1 \%$ \\
\hline Quite unsatisfied & $7.6 \%$ \\
\hline Partially satisfied & $16.7 \%$ \\
\hline Quite satisfied & $36.4 \%$ \\
\hline Totally satisfied & $33.3 \%$ \\
\hline Average (sd) & $3.83(1.16)$ \\
\hline \multicolumn{2}{|c|}{ Support received by WIU practitioners } \\
\hline Totally unsatisfied & $1.5 \%$ \\
\hline Quite unsatisfied & $1.5 \%$ \\
\hline Partially satisfied & $10.6 \%$ \\
\hline Quite satisfied & $24.2 \%$ \\
\hline Totally satisfied & $62.1 \%$ \\
\hline Average (sd) & $4.44(0.86)$ \\
\hline \multicolumn{2}{|c|}{ Collaboration received by colleagues } \\
\hline Totally unsatisfied & $6.1 \%$ \\
\hline Quite unsatisfied & $9.1 \%$ \\
\hline Partially satisfied & $18.2 \%$ \\
\hline Quite satisfied & $30.3 \%$ \\
\hline Totally satisfied & $36.4 \%$ \\
\hline Average (sd) & $3.82(1.20)$ \\
\hline
\end{tabular}

\section{Satisfaction of the Company Contacts}

Fifty-eight questionnaires were collected: $66.7 \%$ were filled in by males, with an average age of 43 years $(\mathrm{SD}=8$; range: $28-64)$.

Overall, the company contacts expressed a high level of satisfaction (Table 3). Specifically, the areas of their main satisfaction were the information received by the practitioners of the WIU, their collaboration and the timeliness of their interventions in the moments of difficulty and, finally, their own involvement in the vocational placement.

\section{Satisfaction of the Caregivers}

Forty-two questionnaires were collected from individuals who were $31 \%$ males, and who were 54 years old, on average $(\mathrm{SD}=15$; range: $20-86)$. Almost half of the caregivers $(52.4 \%)$ were parents, whilst $9.5 \%$ were brothers, or sisters, $11.9 \%$ were spouses, or companions, $7.1 \%$ were son/daughter, $16.7 \%$ were different relatives, and, eventually, just $2.4 \%$ were friends.

The caregivers scored their highest levels of satisfaction on the support that their family members had received by the practitioner of the WIU; soon after, there was the work by their family members, followed by the collaboration that they had received from their colleagues at work (Table 4).

Table 3. Satisfaction of the Company Contacts $(\mathrm{N}=58)$

\begin{tabular}{|c|c|}
\hline $\begin{array}{c}\text { Overall Satisfaction } \\
\text { Average }(\text { sd })\end{array}$ & $4.54(0.44)$ \\
\hline \multicolumn{2}{|c|}{$\begin{array}{c}\text { Collaboration received by WIU } \\
\text { practitioners }\end{array}$} \\
\hline Totally unsatisfied & $0.0 \%$ \\
\hline Quite unsatisfied & $0.0 \%$ \\
\hline Partially satisfied & $1.7 \%$ \\
\hline Quite satisfied & $39.7 \%$ \\
\hline Totally satisfied & $58.6 \%$ \\
\hline Average (sd) & $4.57(0.53)$ \\
\hline \multicolumn{2}{|c|}{$\begin{array}{c}\text { Usefulness of the information received } \\
\text { by WIU practitioners }\end{array}$} \\
\hline Totally unsatisfied & $0.0 \%$ \\
\hline Quite unsatisfied & $0.0 \%$ \\
\hline Partially satisfied & $0.0 \%$ \\
\hline Quite satisfied & $44.8 \%$ \\
\hline Totally satisfied & $55.2 \%$ \\
\hline Average (sd) & $4.55(0.50)$ \\
\hline \multicolumn{2}{|c|}{$\begin{array}{c}\text { Timeliness of the interventions received } \\
\text { by WIU practitioners }\end{array}$} \\
\hline Totally unsatisfied & $0.0 \%$ \\
\hline Quite unsatisfied & $0.0 \%$ \\
\hline Partially satisfied & $1.7 \%$ \\
\hline Quite satisfied & $27.6 \%$ \\
\hline Totally satisfied & $70.7 \%$ \\
\hline Average (sd) & $4.69(0.50)$ \\
\hline \multicolumn{2}{|c|}{$\begin{array}{c}\text { Own involvement in the vocational } \\
\text { placement }\end{array}$} \\
\hline Totally unsatisfied & $0.0 \%$ \\
\hline Quite unsatisfied & $3.4 \%$ \\
\hline Partially satisfied & $8.6 \%$ \\
\hline Quite satisfied & $37.9 \%$ \\
\hline Totally satisfied & $50.0 \%$ \\
\hline Average (sd) & $4.34(0.78)$ \\
\hline
\end{tabular}

\section{Satisfaction of the WIU Practitioners}

Eighty-four questionnaires were collected. The people who completed them were $84.5 \%$ female and their average age was 40 years $(\mathrm{SD}=2$; range: $35-47)$. 
Table 4. Satisfaction of the Caregivers $(N=42)$

\begin{tabular}{|c|c|}
\hline $\begin{array}{c}\text { Overall Satisfaction } \\
\text { Average (sd) }\end{array}$ & $3.78(1.01)$ \\
\hline \multicolumn{2}{|c|}{ Actual work by their family member } \\
\hline Totally unsatisfied & $7.1 \%$ \\
\hline Quite unsatisfied & $4.8 \%$ \\
\hline Partially satisfied & $19.0 \%$ \\
\hline Quite satisfied & $45.2 \%$ \\
\hline Totally satisfied & $23.8 \%$ \\
\hline Average (sd) & $3.74(1.11)$ \\
\hline \multicolumn{2}{|c|}{$\begin{array}{l}\text { Support that their family member } \\
\text { received from WIU practitioners }\end{array}$} \\
\hline Totally unsatisfied & $4.8 \%$ \\
\hline Quite unsatisfied & $4.8 \%$ \\
\hline Partially satisfied & $9.5 \%$ \\
\hline Quite satisfied & $33.3 \%$ \\
\hline Totally satisfied & $47.6 \%$ \\
\hline Average (sd) & $4.14(1.09)$ \\
\hline \multicolumn{2}{|c|}{$\begin{array}{l}\text { Collaboration that their family member } \\
\text { received by colleagues }\end{array}$} \\
\hline Totally unsatisfied & $9.5 \%$ \\
\hline Quite unsatisfied & $11.9 \%$ \\
\hline Partially satisfied & $23.8 \%$ \\
\hline Quite satisfied & $31.0 \%$ \\
\hline Totally satisfied & $23.8 \%$ \\
\hline Average (sd) & $3.45(1.31)$ \\
\hline
\end{tabular}

The area of interest that the practitioners expressed their greater level of satisfaction was the collaboration with the employers, followed by the collaboration with the users themselves during their vocational integration. The area of interest about which the practitioners felt the most dissatisfaction was the collaboration received by the dispatching mental health services (Table 5).

\section{Association Between Program Outcome and Level of Sat- isfaction}

In Table $\mathbf{6}$ are reported the outcomes of the comparisons between the average levels of satisfaction of users, caregivers, practitioners, and company contacts nested within the two possible program outcomes (positive versus negative). All the subjects involved in the study showed higher satisfaction levels in the event of positive outcome $(p<0.05)$.

\section{Outcome Predictors}

The independent variables in the model of multivariate logistic regression that were used trying to predict users' job maintenance (positive versus negative outcomes) are gender, age, diagnosis, total number of interventions received before and after employment in a company, or social cooperative.

The only variable significantly associated with the positive outcome was the total number of interventions received before job placement $(\mathrm{RR}=.963 ; 95 \%$ CI $0.928-0.999 ; \mathrm{p}=$ $.046)$. As the RR is just below 1 , this result indicates a very weak negative association with a positive outcome, i.e., job maintenance resulted weakly associated to a smaller number of interventions received by program users before their placement in a company, or in a social cooperative.

Table 5. Satisfaction of the WIU Practitioners $(\mathrm{N}=\mathbf{8 4})$

\begin{tabular}{|c|c|}
\hline $\begin{array}{c}\text { Overall Satisfaction } \\
\text { Average (sd) }\end{array}$ & $3.84(0.64)$ \\
\hline \multicolumn{2}{|c|}{ Collaboration with the employers } \\
\hline Totally unsatisfied & $1.2 \%$ \\
\hline Quite unsatisfied & $1.2 \%$ \\
\hline Partially satisfied & $23.8 \%$ \\
\hline Quite satisfied & $42.9 \%$ \\
\hline Totally satisfied & $31.0 \%$ \\
\hline Average (sd) & $4.01(0.84)$ \\
\hline \multicolumn{2}{|c|}{ Collaboration with the colleagues } \\
\hline Totally unsatisfied & $1.2 \%$ \\
\hline Quite unsatisfied & $6.0 \%$ \\
\hline Partially satisfied & $17.9 \%$ \\
\hline Quite satisfied & $28.6 \%$ \\
\hline Totally satisfied & $46.4 \%$ \\
\hline Average (sd) & $4.13(0.99)$ \\
\hline \multicolumn{2}{|c|}{$\begin{array}{l}\text { Collaboration received by the dispatching } \\
\text { mental health services }\end{array}$} \\
\hline Totally unsatisfied & $6.0 \%$ \\
\hline Quite unsatisfied & $21.4 \%$ \\
\hline Partially satisfied & $36.9 \%$ \\
\hline Quite satisfied & $22.6 \%$ \\
\hline Totally satisfied & $13.1 \%$ \\
\hline Average (sd) & $3.15(1.09)$ \\
\hline \multicolumn{2}{|c|}{$\begin{array}{c}\text { Collaboration of the user in his/her } \\
\text { vocational placement }\end{array}$} \\
\hline Totally unsatisfied & $0.0 \%$ \\
\hline Quite unsatisfied & $4.8 \%$ \\
\hline Partially satisfied & $23.8 \%$ \\
\hline Quite satisfied & $34.5 \%$ \\
\hline Totally satisfied & $36.9 \%$ \\
\hline Average (sd) & $4.04(0.90)$ \\
\hline
\end{tabular}


Table 6. Satisfaction and Outcome

\begin{tabular}{|c|c|c|c|c|}
\hline Satisfaction & Work Outcome & $\mathbf{N}$ & Average (sd) & P-value \\
\hline $\begin{array}{l}\text { Company } \\
\text { Contacts }\end{array}$ & $\begin{array}{l}\text { Negative } \\
\text { Positive }\end{array}$ & $\begin{array}{l}17 \\
39\end{array}$ & $\begin{array}{l}4.27(.43) \\
4.66(.39)\end{array}$ & .002 \\
\hline Caregivers & $\begin{array}{l}\text { Negative } \\
\text { Positive }\end{array}$ & $\begin{array}{l}11 \\
30\end{array}$ & $\begin{array}{l}2.81(.98) \\
4.15(.77)\end{array}$ & .000 \\
\hline $\begin{array}{c}\text { WIU } \\
\text { Practitioners }\end{array}$ & $\begin{array}{l}\text { Negative } \\
\text { Positive }\end{array}$ & $\begin{array}{l}28 \\
54\end{array}$ & $\begin{array}{l}3.46(.56) \\
4.02(.60)\end{array}$ & .000 \\
\hline Users & $\begin{array}{l}\text { Negative } \\
\text { Positive }\end{array}$ & $\begin{array}{l}18 \\
46\end{array}$ & $\begin{array}{l}3.29(1.04) \\
4.35(.55)\end{array}$ & .001 \\
\hline
\end{tabular}

\section{DISCUSSION}

This study dealt with the daily practice of vocational placement service with the aim of identifying any variables predictive of its outcomes, whose main one is employment maintenance. The research shows that about $65 \%$ of the subjects involved in a supported work program kept their employment over time. This study also stresses the validity of using supported employment as an effective strategy to help people with mental disorders to obtain and keep competitive jobs.

At an international level, it has now been agreed since some time, that people receiving a program, like the IPS, perform on the job more effectively even in competitive employment, and do it longer, than those who undergo traditional professional rehabilitative approaches. Moreover, it would seem that receiving IPS could lower the probability of suffering more hospitalizations and could even lower the risk of dropping out from work [27].

This present study shows that the total number of interventions, received before job placement, is the only variable somehow associated with the program outcome. This result indicates the tendency of job maintenance to be, albeit weakly, negatively linked with the number of interventions received after the beginning of the program, but before the users' placement in a company, or in social cooperative. This result could be at odd with the results by Leff and collaborators who, in their study [26], found that the amount of job support received was significantly associated with the number of months that their patients spent in their first competitive job. However, these authors did not consider whether job support was given, or not, before users' job placement, opening the possibility that their patients had received more job support just because they had spent more time on the job. Of course, this would invalidate the hypothesis that job support could have been a causal factor associated with job maintenance. In this study the causal role between job support and job maintenance is, therefore, questionable.

A negative relationship between prior support and job maintenance was found by John and collaborators. In their study they proved that two different categories of financial support (social security disability income and supplemental security income), before the beginning of supported employment experience, were negatively associated with future work status [28]. Other studies have explored the im- pact of support on job maintenance, in the IPS model, but the results are still controversial. In fact, little direct evidence exists supporting the hypothesis that ongoing support contributes to job maintenance, even though it is one of the core tenets of the IPS model. In a recent study Bond and Kukla [29] found a moderate correlation between intensity of employment specialist support and duration of employment, but an important question not answered by their study is whether other sources of support, such as mental health case managers and natural supports, such as family members, can substitute for or augment the assistance of employment specialists. In another study, McGuire and collaborators [30] found that the total IPS contacts were positively associated with weeks worked and that the client background characteristics did not predict service intensity. However, one relationship indicated that participants who were better performers had received more services. Conversely, other studies had found that having more severe symptoms was associated with more intense support.

Also in our study, the results could be attributed to the number of interventions received before entering the work environment, as it could be a proxy of seriousness. When users show higher levels of psychopathology, - or lower levels of psychosocial functioning, and/or a worse background of work experience - they need greater ongoing support by practitioners and that could hinder the attainment of a positive outcome.

Anyway, the above reported studies show that further research on job support is needed, to improve our understanding of variables associated with employment outcomes.

Finally, we have to acknowledge that the possibility of deriving conclusions from this study is hindered by a number of limitations, as follows. Lack of information on subjects previous work experiences, missing the mean follow-up period of job maintenance, lacking information about subjects' psychopathology and, last, but not least, lacking information on personal and social functioning and cognitive profile of tested users. The lack of these data makes it, therefore, impossible to estimate what effects the above-mentioned variables would have had on, both, the choice of entering a specific vocational placement program, and on job maintenance. We cannot be sure of which factors really led to the premature loss of their employment by those people who had a negative outcome. There are many ways that disabilities can affect the capacity to perform effectively on the job. It might simply be that not all people with severe mental disorders can be led to obtain and maintain a job.

All these shortages undoubtedly represent critical elements of this study, but they were unavoidable because they are the consequence of the outlook of Italian services dealing with the mental health patients and/or with their work integration. In Italy, mental health practitioners working in this field do not usually assess, through standardized instruments, the severity of symptoms, the level of disability and the neuropsychological functioning of their patients. In addition, has we were dealing with a retrospective study; we were able to assess just the data that had been collected in a routine service.

We considered satisfaction important and chose to investigated as the dependent variable in our study, as users are 
becoming more and more active whenever it comes to take decisions about their future and their care. Therefore, they have greater influence, than they had in the past, to change and improve the quality of services by reporting the satisfaction of their experiences. Data show that the area where, both, users as well as their caregivers and company contacts too, express a greater level of satisfaction, is the support received by the practitioners of the WIU. It is possible that this result had been influenced by a social desirability bias, but such satisfaction could also depend on the good support supplied by service practitioners and be the main variable positively affecting the relative effectiveness of the program [31]. However, no other variables, which could be associated with a lower, or greater, level of satisfaction, and to the main outcome as well, were collected. Candidate variables would be, e.g., salary, the number of working hours, the type of work, etc.

Finally, a few words must be spent on the satisfaction by the practitioners of the WIU, which scored the lowest in the area of the collaboration received by the dispatching mental health services. This result opens an important reflection on the need to increase the collaboration between the different services that, at various levels, take care of mental disorders. No matter how beneficial the effect that job status and work experiences play on the progress of mental illnesses, insufficient interest still seems to persist toward the role that work rehabilitation could play in the treatment of people with mental disorders. It still seems too rare, for mental health practitioners, to consider unemployment a significant stressor for people under their care; but this is a factor that can influence, not just clinical recovery, but also the probability of relapse. Working can indeed be a decisive element for the development of an adequate feeling of self-esteem and for the attainment of a minimum amount of social status by people suffering from mental disorders. It is, therefore, necessary to promote and implement a system of care foreseeing an effective integration of all the services, which deal with mental health, realizing an overall total charge of the person with psychiatric disabilities. Only through a psychosocial rehabilitation thus conceived it would be possible to boost the real social reintegration of people suffering from these disorders.

\section{CONFLICT OF INTEREST}

The authors declare they have not conflict of interest regarding this paper. This work was supported by the Italian Institute of Health (ex article 56, Law 289/2002, $\mathrm{N}^{\circ}$ $534 \mathrm{M} / 7)$.

\section{ACKNOWLEDGEMENT}

Declared none.

\section{REFERENCES}

[1] Holzner B, Kemmler G, Meise U. The impact of work-related rehabilitation on the quality of life of patients with schizophrenia. Soc Psychiatry Psychiatr Epidemiol 1998; 3: 624-631.

[2] Burns T, Catty J, White S, et al. The impact of supported employment and working on clinical and social functioning: Results of an international study of individual placemente and support. Schizophr Bull 2009; 35(5): 949-58.
[3] Lehman AF, Steinwachs DS. Patterns of usual care for schizophrenia: initial results from the Schizophrenia Patient Outcome Research Team (PORT) Client Survey. Schizophr Bull 1998; 24: 1120.

[4] Bond GR, Drake RE, Mueser KT, et al. An update on supported employment for people with severe mental illness. Psychiatr Serv 1997; 48: 335-346.

[5] Boardman J, Grove B, Perkins R, et al. Work and employment for people with psychiatric disabilities. Br J Psychiatry 2003; 182: 4678.

[6] Thornicroft G, Tansella M, Becker T, et al. The personal impact of schizophrenia in Europe. Schizophr Res 2004; 69: 125-32.

[7] Marwaha S, Johnson S, Bebbington P, et al. Rates and correlates of employment in people with schizophrenia in the UK, France and Germany. Br J Psychiatry 2007; 191: 30-7.

[8] Farkas MD, Rogers ES, Thurer S. Rehabilitation outcome of longterm hospital patients left behind by deinstitutionalization. $\mathrm{H}$ and CP 1987; 38(8): 864-70.

[9] Cook JA, Lehman AF, Drake R, et al. Integration of psychiatric and vocational services: a multisite randomized, controlled trial of supported employment. Am J Psychiatry 2005; 162(10): 1948-56.

[10] Blank L, Peters J, Pickvance S, et al. A Systematic Review of the factors which Predict Return to Work for People Suffering Episodes of Poor Mental Health. J Occup Rehabil 2008; 18: 27-34.

[11] McGurk SR, Mueser KT, Harvey PD, et al. Cognitive and Symptom Predictors of Work Outcomes for Clients With Schizophrenia in Supported Employment. Psychiatr Serv 2003; 54(8): 1129-35.

[12] Tsang HW, Leung AY, Chung RC, et al. Review on vocational predictors: a Systematic review of predictors of vocational outcomes among individuals with schizophrenia: an update since 1998. Aust N Z J Psychiatry 2010; 44(6): 495-504.

[13] Stansfeld SA, Fuhrer R, Head J. Impact of common mental disorders on sickness absence in an occupational cohort study. Occup Environ Med 2011; 68(6): 408-13.

[14] Stansfeld SA, Rael EG, Head J, et al. Social support and psychiatric sickness absence: a prospective study of British civil servants. Psychol Med 1997; 27(1): 35-48.

[15] Michie S, Williams S. Reducing work related psychological ill health and sickness absence: a literature review. Occup Environ Med 2003; 60: 3-9.

[16] Catty J, Lissouba P, White S, et al. Predictors of employment for people with severe mental illness: results of an international sixcentre randomised controlled trial. Br J Psychiat 2008; 192(3): 22431.

[17] Kin Wong K, Chiu R, Tang B, et al. A randomized controlled trial of a supported employment program for persons with long-term mental illness in Hong Kong. Psychiatr Serv 2008; 59(1): 84-90.

[18] Becker DR, Drake RE. Individual placement and support: A community mental health center approach to vocational rehabilitation. Community Ment Health J 1994; 30: 193-206.

[19] Salyers MP, Becker DR, Drake RE, et al. A ten-years follow-up of a supported employment program. Psychiatr Serv 2004; 55: 302-8.

[20] Becker B, Whitley R, Bailey EL, et al. Long-Term Employment Trajectories Among Participants With Severe Mental Illness in Supported Employment. Psychiatr Serv 2007; 58(7): 922-8.

[21] McGurk SR, Mueser KT. Cognitive and clinical predictors of work outcomes in clients with schizophrenia receiving supported employment services: 4-years follow-up. Adm Policy Ment Health 2006; 33(5): 598-606.

[22] Nithsdale V, Davies J, Croucher P. Psychosis and the experience of employment. J Rehabil 2008; 18: 175-82.

[23] Russinova Z, Bloch PP, Lyass A. Patterns of employment among individuals with mental illness in vocational recovery. J Psychosoc Nurs Ment Health Serv 2007; 45(12): 48-54.

[24] Campbell K, Bond GR, Drake RE, et al. Client predictors of employment outcomes in high-fidelity supported employment: a regression analysis. J Nerv Ment Dis 2010; 198(8): 556-63.

[25] Buizza C, Ghilardi A, Imbasciati A. La riabilitazione. In: Imbasciati A, Margiotta M, Eds. Compendio di psicologia per operatori sanitari. Padova: Piccin 2005; pp. 427-43.

[26] Leff HS, Cook JA, Gold PB, et al. Effects of job development and job support on competitive employment of persons with severe mental illness. Psychiatr Serv 2005; 56: 1237-44.

[27] Bond GR, Drake RE. Making the Case for IPS Supported Employment. Adm Policy Ment Health 2014; 41(1):69-73. 
[28] Jones CJ, Perkins DV, Born DL. Predicting work outcomes and service use in supported employment services for persons with psychiatric disabilities. Psychiatr Rehabil J 2001; 25: 53-9.

[29] Bond GR, Kukla M. Impact of follow-along support on job tenure in the Individual Placement and Support model. J Nerv Ment Dis 2011; 199: 150-5.
[30] McGuire AB, Bond GR, Clendenning D, et al. Service intensity as a predictor of competitive employment in an Individual Placement and Support program. Psychiatr Serv 2011; 62: 1066-72.

[31] Kukla M, Bond GR. The working alliance and employment outcomes for people with severe mental illness enrolled in vocational programs. Rehabil Psychol 2009; 54(2): 157-63.

Received: February 14, 2013

Revised: December 20, 2013

Accepted: December 20, 2013

(C) Buizza et al.; Licensee Bentham Open.

This is an open access article licensed under the terms of the Creative Commons Attribution Non-Commercial License (http://creativecommons.org/licenses/by-nc/3.0/) which permits unrestricted, non-commercial use, distribution and reproduction in any medium, provided the work is properly cited. 